\title{
Is there a need for a new staging system in early lung cancer?
}

\author{
Samuel Kim, MD
}

\author{
From the Department of Surgery, University of Arizona, Tucson, Ariz. \\ Disclosures: Author has nothing to disclose with regard to commercial support. \\ Received for publication Feb 18, 2016; accepted for publication Feb 19, 2016; available ahead of print March 11, \\ 2016. \\ Address for reprints: Samuel Kim, MD, Department of Surgery, University of Arizona, 1501 N. Campbell Ave, \\ \#4302, Tucson, AZ 85724 (E-mail: skim@surgery.arizona.edu). \\ J Thorac Cardiovasc Surg 2016;151:1569-70 \\ $0022-5223 / \$ 36.00$ \\ Copyright (C 2016 by The American Association for Thoracic Surgery \\ http://dx.doi.org/10.1016/j.jtcvs.2016.02.040
}

A significant change in the pathologic classification of lung cancer occurred with the publication in 2011 of a new lung adenocarcinoma classification system under the sponsorship of the International Association for the Study of Lung Cancer (IASLC), the American Thoracic Society (ATS), and the European Respiratory Society (ERS). ${ }^{1}$ The term "bronchioloalveolar carcinoma," which was previously used to describe a broad spectrum of morphologically diverse tumors, was discontinued because it was recognized that each subtype contained disparate clinical and molecular properties. The growth patterns of former bronchioloalveolar carcinomas in the stricter sense are now designated as "lepidic." The different tumors with lepidic growth are now classified in a continuous spectrum ranging from atypical adenomatous hyperplasia to adenocarcinoma in situ (AIS) to minimally invasive adenocarcinoma (MIA) and, ultimately, to lepidic predominant adenocarcinoma. However, classifying patients with these lesions according to American Joint Committee on Cancer (AJCC) TNM staging has been problematic because purely lepidic lesions and small predominantly invasive adenocarcinomas both would be classified as stage I cancer, although there is a clear difference in patient outcomes, which might affect treatment strategies.

The article by Wilshire and colleagues ${ }^{2}$ highlights this shortcoming of the current TNM staging system and illustrates the advantages of the discriminating ability of the IASLC/ATS/ERS system. In their study, 138 patients with stage I lepidic-associated pulmonary lesions were histologically recategorized using the IASLC/ATS/ERS system, the AJCC staging system, or the "integrated" classification systems to determine which approach best predicts disease recurrence and overall survival (OS). Their results confirmed a low recurrence rate and excellent disease-free survival (DFS) and OS for the patients with AIS and MIA compared with patients with lepidic-associated invasive adenocarcinoma. The 5-year DFS in patients with AIS and MIA was $100 \%$ and $96 \%$, respectively, and the OS was $100 \%$ for both. The patients with invasive adenocarcinoma had a 5 -year DFS of $80 \%$ and an OS of $90 \%$. In contrast, if tumors were classified using the AJCC TNM system, there

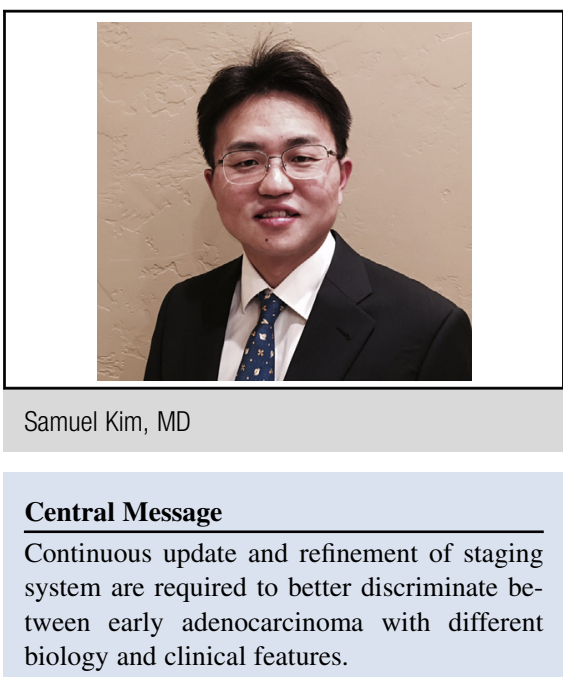

See Article page 1561.

was a DFS of $87 \%$ and OS of $94 \%$ for patients with stage I disease, thus underestimating the DFS and OS for those with AIS and MIA features while overestimating DFS and OS for those with invasive adenocarcinoma. Reclassifying AIS and MIA as "stage 0," as proposed by the authors, appears to remedy this. The patients with integrated stage 0 disease $(98 \%)$ had a significantly higher 5-year DFS in comparison with patients with stage I $(80 \%)$. Five-year OS for patients with stage 0 disease in the integrated classification was $100 \%$ compared with $90 \%$ for patients with stage I. This proposed modification to the staging system appears to better correlate with clinical outcomes of the patients. Of note, it was interesting to observe that most patients with AIS and MIA underwent wedge resection, whereas patients with lepidic-associated invasive carcinoma underwent lobectomy.

This study has several modest limitations worth mentioning, the major concern being the possibility of pathologic sampling errors. Only a small portion of the tumor sample was reviewed in their retrospective analysis; a single section could have missed an invasive component elsewhere. The second issue is one of the generalizability of the study. This is a single institution study with interpretation performed by a single group of thoracic pathologists. The pathologic interpretation can be influenced by interobserver variability, sample quality, slide preparation, and improper interpretation of the specimen due to lack of experience. ${ }^{3}$ Thunnissen and colleagues ${ }^{4}$ found that artifacts such as atelectasis and inflammation can obscure the diagnosis of a "lepidic" pattern without proper education and 
sufficient experience. ${ }^{4}$ Precise definitions of the histologic appearance and more experience with the proposed modification to the standard staging system are needed to attain reliable and reproducible identification of purely in situ and minimally invasive disease. Therefore, it is not surprising that other institutions have reported different outcomes. In their retrospective analysis of 104 patients with T1N0M0 adenocarcinoma, Weissferdt and colleagues ${ }^{5}$ have reported that the histologic characteristics including tumor differentiation and the percentage of lepidic or bronchioloalveolar components did not show any statistically significant values in terms of survival. ${ }^{5}$ A multi-institutional study to determine reproducibility of the correlation between histopathologic subtypes and degree of invasion in adenocarcinoma to clinical outcome is needed before accepting this study to be a definitive "North American Experience."

Despite its limitations, this article by Wilshire and colleagues ${ }^{2}$ is timely and highlights a possible deficiency in the current TNM staging system and provides an important step in refining the staging system tailored to individual patients. The authors should continue their current efforts by designing a multi-institution study to confirm their institutional findings. Also, it would be important to learn if this new staging system in patients with stage 0 disease can be used to make preoperative or postoperative decisions.

\section{References}

1. Travis WD, Brambilla E, Noguchi M, Nicholson AG, Geisinger K, Yatabe Y, et al. International Association for the Study of Lung Cancer/American Thoracic Society/European Respiratory Society international multidisciplinary classification of lung adenocarcinoma. J Thorac Oncol. 2011;6:244-85.

2. Wilshire C, Louie B, Horton P, Castiglioni M, Aye RW, Farivar AS, et al. Comparison of outcomes for patients with lepidic pulmonary adenocarcinoma defined by two staging systems: a North American experience. J Thorac Cardiovasc Surg. 2016;151:1561-8.

3. Warth A, Cortis J, Fink L, Fisseler-Eckhoff A, Geddert H, Hager T, et al. Training increases concordance in classifying pulmonary adenocarcinomas according to the novel IASLC/ATS/ERS classification. Virchows Arch. 2012;461: 185-93.

4. Thunnissen E, Beliën JA, Kerr KM, Chung JH, Flieder DB, Noguchi M, et al. In compressed lung tissue microscopic sections of adenocarcinoma in situ may mimic papillary adenocarcinoma. Arch Pathol Lab Med. 2013;137:1792-7.

5. Weissferdt A, Kalhor N, Marom EM, Benveniste MF, Godoy MC, Correa AM, et al. Early-stage pulmonary adenocarcinoma (T1NOM0): a clinical, radiological, surgical, and pathological correlation of 104 cases. The MD Anderson Cancer Center Experience. Mod Pathol. 2013;26:1065-75. 